\title{
An Investigation on College Students' Basic Aesthetic Quality and the Needs of Aesthetic Education Curriculum-Empirical Evidence from Ten Universities Data in China
}

\author{
Zezhou Ye, Hui Xiang \\ College of Educational Science, Liupanshui Normal University, Liupanshui 553000, GuiZhou, China
}

\begin{abstract}
The research defines the basic aesthetic qualities and divides them into three parts: aesthetic consciousness, common sense, and behavior. Empirical evidence from more than 1000 college students of ten universities showed that many students still lack basic aesthetic knowledge and skills, and there are also significant differences in gender, location, and qualification. Therefore, college students have a relatively large demand for aesthetic education curriculum, especially in the arts. But obviously, the current aesthetic education curriculums in colleges and universities cannot meet the needs of students, and it is even more difficult to guarantee the aesthetic ability of students who lack art education in primary and secondary schools. Therefore, it is necessary to make up for deficiency in university courses, and to carry out professional-based and even interdisciplinary and cross-border aesthetic courses can achieve the goals of aesthetic education in universities.
\end{abstract}

Keywords: Aesthetic quality, Demand for aesthetic education curriculum, Aesthetic education compensation.

Aesthetic education is an intentional undertaking designed to nurture appreciative, reflective, cultural, participatory engagements with the arts by enabling learners to notice what is there to be noticed[1]. In fact, aesthetic education remains inaccessible to some countries in their educational career. As a country with a long history and prosperous culture, China has a tradition of aesthetic education. However, due to historical and practical reasons, there is still a lack of aesthetic education in scholastic education. Many rural schools and schools in remote areas don't have enough teachers and curriculum resources for art education. This also directly leads to the students in colleges and universities faced with difficulty in carrying out more profound and advanced aesthetic education. Therefore, the research investigates the aesthetic quality of college students and aesthetic education curriculum in order to design an aesthetic education system that better meets the needs of college students.

\section{Explanation of the Concepts}

\subsection{The Basic Aesthetic Qualities of College Students}

Aesthetic quality is an organic part of humanistic quality. Chinese scholar Dr. Zhao believes that aesthetic quality is the aesthetic psychology with aesthetic common sense, standard and behavior as the main indicators[2]. Aesthetic quality is usually understood as a kind of psychological ability. The basic aesthetic quality of college students is more inclined to the aesthetic behavior ability based on the aesthetic experience, especially the aesthetic awareness, common sense and behavior embodied by the individual under the influence of the aesthetic education experience at the primary education stage and the family and social aesthetic education environment. Among, aesthetic consciousness, which forms, develops and dominates in people's aesthetic activities, is the general term of the thought, cognition, emotion and volition[3]. The basic aesthetic consciousness refers to whether an individual can perceive the existence of beauty, know the value and standard of beauty and his aesthetic ideal, which are in the basic position in the framework of the basic aesthetic qualities of college students. Basic aesthetic common sense refers to college students' understanding of beauty, aesthetics and aesthetic education. And basic aesthetic behavior refers to the types and fields of college students' aesthetic activities, including natural beauty, social beauty, art beauty and scientific beauty. "It is important that students generate and explore aesthetic concepts before concepts are identified as such and before concepts are related to preestablished theories.’'[4]

\subsection{Demands of Aesthetic Education Curriculum for College Students}

From multiple government documents, the current education authorities attach great importance to the aesthetic education curriculum, but it more reflects the lack of aesthetic education curriculum in schools of various levels. At present, the personality development of college students is becoming diversified, and the demand for aesthetic education courses is becoming complicated. At the same time, in the interweaving of Eastern and Western cultures, the revival of traditional culture and the ever-changing modern culture, college students will start from their personal interests and hobbies, the rational thinking of personal development, and ask for aesthetic courses to cultivate personal sentiment, improve cultural accomplishment and even relieve the pressure of professional learning in the higher education curriculum system. On the other hand, the aim of higher education is to cultivate high-level specialized talents, and majors are the basic units of higher education. Students majoring in aesthetics (philosophy), pedagogy, art, and various other subjects and specialities have different demands for aesthetic education courses. Therefore, the demand for aesthetic education curriculum will be investigated from three aspects: art education, aestheticized education of subjects and 
specialities and interdisciplinary aesthetic education. Among them, the art education refers to whether students have received art training and have relevant art skills. On the one hand, aestheticized education of subjects and specialities emphasizes the aesthetic cognition of subjects and specialities, but also focuses on implementing them in the teaching of professional courses and even offering related professional aesthetic curriculum. Interdisciplinary aesthetic education is a concentrated expression of the ubiquity of beauty. It is also a common pursuit of human activities. In higher education, it is a pleasant experience in various disciplines and professions.

\section{Survey Design}

\subsection{Survey Content}

According to the definition of basic aesthetic quality and aesthetic education curriculum needs for college students, the survey contents are as follows in Table 1.

Table 1: The content of aesthetic education survey in colleges and universities

\begin{tabular}{|c|c|c|}
\hline $\begin{array}{l}\text { First level } \\
\text { dimensions }\end{array}$ & $\begin{array}{l}\text { Second level } \\
\text { dimensions }\end{array}$ & Object \\
\hline \multirow{6}{*}{$\begin{array}{l}\text { 1.basic aesthetic } \\
\text { quality }\end{array}$} & $\begin{array}{l}\text { 11.aesthetic } \\
\text { consciousness }\end{array}$ & $\begin{array}{l}\text { 111.know that beauty exists } \\
\text { 112. aesthetic standards to } \\
\text { everything } \\
\text { 113.individual aesthetic } \\
\text { ideal }\end{array}$ \\
\hline & \multirow{2}{*}{$\begin{array}{l}\text { 12.aesthetic } \\
\text { common sense }\end{array}$} & $\begin{array}{l}\text { 121.what is beauty } \\
\text { 122.what is aesthetics }\end{array}$ \\
\hline & & $\begin{array}{l}\text { 123. what is aesthetic } \\
\text { education }\end{array}$ \\
\hline & \multirow{3}{*}{$\begin{array}{l}\text { 13.aesthetic } \\
\text { behavior }\end{array}$} & $\begin{array}{l}\text { 131. esthetic activities for } \\
\text { nature }\end{array}$ \\
\hline & & $\begin{array}{l}\text { 132. esthetic activities to } \\
\text { society }\end{array}$ \\
\hline & & $\begin{array}{l}\text { 133. esthetic activities of art } \\
\text { 134. esthetic activities for } \\
\text { science }\end{array}$ \\
\hline \multirow{6}{*}{$\begin{array}{l}\text { 2.basic needs of } \\
\text { aesthetic } \\
\text { education }\end{array}$} & \multirow{2}{*}{ 21.art education } & 211. arts training \\
\hline & & 212. artistic technique \\
\hline & $\begin{array}{l}\text { 22.aestheticized } \\
\text { education of }\end{array}$ & $\begin{array}{l}\text { 221. professional aesthetic } \\
\text { cognition }\end{array}$ \\
\hline & $\begin{array}{l}\text { subjects and } \\
\text { specialities }\end{array}$ & $\begin{array}{l}\text { 222. professional esthetic } \\
\text { education curriculum }\end{array}$ \\
\hline & & 231.beauty is an all- \\
\hline & $\begin{array}{l}\text { 23.interdisciplinary } \\
\text { aesthetic education }\end{array}$ & $\begin{array}{l}\text { pervading presence } \\
232 \text {.beauty represents itself } \\
\text { with diversity and integrity }\end{array}$ \\
\hline
\end{tabular}

\subsection{Survey Tools}

According to the above analysis of the basic concepts and the survey content, a semi-open questionnaire for "Basic Aesthetic Quality and Educational Appeals of College Students" is compiled. Then, based on the evaluation of three experts and the feedback of forty initial test questionnaires, the final questionnaire was modified and formed. The questionnaire mainly includes basic information, six singlechoice, ten multiple-choice and four short-answer questions. Among, questions two, four, five, seven, eight, seventeen, eighteen, nineteen are about basic aesthetic qualities of college students. Questions one, three, six, ten, eleven, twelve, thirteen, fourteen, sixteen are used to investigate the needs of aesthetic education curriculums.

\subsection{Respondent}

This investigation altogether provides paper questionnaires 1000, the actual recovery of 824 copies, of which 762 valid questionnaires. At the same time, totally 300 electronic questionnaires were sent out, the actual recovery of 300 copies, of which 290 valid questionnaires. The survey involved a total of 96 majors, 33 colleges and universities. The basic information as shown in Table 2 .

Table 2: Respondents region distribution

\begin{tabular}{ccccc}
\hline $\begin{array}{c}\text { Item } \\
\text { classification }\end{array}$ & Dimension & $\begin{array}{c}\text { Co } \\
\text { de }\end{array}$ & $\begin{array}{c}\text { Number of } \\
\text { respondent }\end{array}$ & $\begin{array}{c}\text { Percent } \\
\text { age }\end{array}$ \\
\hline \multirow{2}{*}{ gender } & male & {$[1]$} & 381 & $36.22 \%$ \\
location of & female & {$[2]$} & 671 & $63.78 \%$ \\
their home & countryside & {$[1]$} & 428 & $40.68 \%$ \\
qualification & undergraduate & {$[2]$} & 624 & $59.32 \%$ \\
& postgraduate & {$[2]$} & 797 & $75.76 \%$ \\
& freshman; & {$[1]$} & 116 & $24.24 \%$ \\
& sophomore & {$[2]$} & 168 & $15.03 \%$ \\
& junior & {$[3]$} & 328 & $31.18 \%$ \\
grade & senior & {$[4]$} & 185 & $17.59 \%$ \\
& first grade & {$[5]$} & 113 & $10.74 \%$ \\
& postgraduate & & & \\
& second grade & {$[6]$} & 142 & $13.50 \%$ \\
& postgraduate & & & \\
\hline
\end{tabular}

\section{Investigation and Analysis}

\subsection{The Basic Aesthetic Qualities of College Students}

University is an organization for cultivation of high-level talents and plays an irreplaceable role in the overall development of students. From the survey data, this paper analyzes the basic aesthetic qualities of college students in the new era and the needs of aesthetic education courses and explores the aesthetic characteristics of college students.

\subsubsection{Aesthetic consciousness of college students}

Firstly, college students' perception of beauty in daily life. Shopping is one of the daily behaviors of college students, and it is affected by many factors such as college students' finances, practicality and aesthetic character. Whether to consider beauty actually reflects the psychological considerations of the factors of beauty when college students make choices. To a certain extent, it reflects the aesthetic consciousness of college students. The results reveal that beauty is an important factor in the daily life of college students. Whereas over $90 \%$ of the college students consider beauty when doing things, but $6.7 \%$ of college students still don't consider too much and even don't take into consideration at all the element of beauty when they go shopping. This shows that college students have a strong aesthetic consciousness in the new era, and few students with vague aesthetic consciousness cannot be ignored.

At the same time, it's comparing the aesthetic consciousness of college students of different genders, location of their home, and educational backgrounds. The results are shown in the following table. On the whole, the college students of different genders, location of their home and grades are averaged less 
than 2.5, which has again proved the important influence of beauty of college students to shopping. However, college students of different gender and educational background have significant differences in their consideration of beauty. In the dimension of gender, the average score was higher for females than for males, and the female college students pay more attention to beauty factors when shopping. In educational background dimension, the average score was higher for undergraduate than for postgraduate, and the aesthetic considerations of postgraduate are more obvious when shopping.

Table 3: Comparison of college students' aesthetic consciousness

\begin{tabular}{ccccccc}
\hline & Dimension & $N$ & $M$ & $S D$ & $t$ & sig. \\
\hline \multirow{2}{*}{ Gender } & Male & 381 & 2.4 & 0.941 & \multirow{2}{*}{$7.01^{* * *}$} & \multirow{2}{*}{0.000} \\
Location of & Female & 671 & 2.0 & 0.884 & & \\
Their Home & City & 624 & 2.2 & 0.881 & -1.57 & 0.118 \\
Qualification & Undergraduate & 797 & 2.2 & 0.956 & \multirow{2}{*}{$6.06^{* *}$} & \multirow{2}{*}{0.000} \\
& Postgraduate & 255 & 1.8 & 0.767 & & \\
\hline
\end{tabular}

Annotation: *mean $\mathrm{P}<0.05$, great difference; **mean $\mathrm{P}<0.01$, significant difference.

Secondly, the aesthetic standards of college students' daily behavior are the yardsticks for college students to judge the beauty and ugliness in various activities. Under the same social background, college students' aesthetic standards should have commonality[5]. The question item sets "one's current interests and hobbies", "public opinion and fashion" and "ideal standard or realm" as alternative answers. The results show that $58.3 \%$ of college students choose "their interests and hobbies", and there are at least $13.5 \%$ students choosing "public opinion and fashion" in judging the beauty and ugliness. With the development of modern social and economic diversification, college students no longer evaluate the beauty and ugliness with rigid and dogmatic educational thoughts, the display of individuality and self-judgment.

By comparing college students of different genders, location of their home, and educational background, it is found that there is no significant difference in this item. This shows that whether male, female, rural students, urban students, undergraduates or postgraduates judge the beauty and ugliness, they all highlight individual preferences and ideals, while downplaying the influence of public opinion and popular elements. There are relatively few copycat aesthetic standards, which can be considered as society created prosperous economy and magnificent civilization and the development of college students' individualized development.

Thirdly, the judgment of college students on popular things. With the development of market economy and culture, appearance has gradually become a kind of image capital, an intuitive and effective expression symbol recognized by others. Plastic surgery means changing the appearance of an individual through medical means, including both larger overall surgery and smaller miniature plastic surgery, which can effectively change the appearance defects of college students, but there are also many disputes about these "artificial beauties". In this case, what kind of aesthetic standard is upheld becomes the main basis for disputes. The results of the survey showed that only $7.1 \%$ of students expressed their willingness to undergo plastic surgery, $29.7 \%$ of college students expressed opposition, and $21.7 \%$ of college students expressed neutrality. This also shows that current college students are more tolerant of "artificial beauties".

Table 4: Comparison of college students' aesthetic standards

\begin{tabular}{ccccccc}
\hline & Dimension & $N$ & $M$ & $S D$ & $t$ & sig. \\
\hline \multirow{2}{*}{ Gender } & Male & 381 & 1.75 & 0.89 & \multirow{2}{*}{1.56} & \multirow{2}{*}{0.119} \\
Location of & Female & 671 & 1.66 & 0.87 & & \\
Their Home & Countryside & 428 & 1.70 & 0.88 & - & \multirow{2}{*}{0.995} \\
Qualification & 624 & 1.70 & 0.88 & 0.01 & \\
& Undergraduate & 797 & 1.69 & 0.87 & - & 0.800 \\
& Postgraduate & 255 & 1.71 & 0.91 & 0.25 & \\
\hline
\end{tabular}

By comparing college students of different genders, location of their home, and educational level, it is only found that there are significant differences between male and female, and the average is more likely to be opposed, while female tend to "agree but don't plan to do it".

Table 5: Comparison of college students' views on artificial beauty

\begin{tabular}{ccccccc}
\hline & Dimension & $N$ & $M$ & $S D$ & $t$ & sig. \\
\hline \multirow{2}{*}{ Gender } & Male & 381 & 3.12 & 1.26 & \multirow{2}{*}{$2.62 * *$} & \multirow{2}{*}{0.009} \\
Location of & Female & 671 & 2.90 & 1.30 & & \\
Countryside & 428 & 2.95 & 1.34 & \multirow{2}{*}{0.56} & \multirow{2}{*}{0.580} \\
Qualific Home & City & 624 & 3.00 & 1.26 & & \\
& Undergraduate & 797 & 3.01 & 1.30 & \multirow{2}{*}{1.33} & 0.183 \\
\hline
\end{tabular}

Annotation: $*$ mean $\mathrm{P}<0.05$, great difference; $* *$ mean $\mathrm{P}<0.01$, significant difference.

Fourthly, the aesthetic ideals of college students. Aesthetic ideals are the highest level of human pursuit of beauty. Under certain historical conditions, ideals sublimated from individual aesthetic experience penetrates into individual aesthetic feelings. [6] The aesthetic ideals of college students are not only the expression of their aesthetic psychology, but also the expression of their social value and even the spiritual world. The item design is "beautiful, kindness, fashion, truth, wealth, authority, wisdom, harmony, sincerity and grotesque" as alternative options.

Results: It showed that kindness $(70.60 \%)$, wisdom $(64.60 \%)$ and sincerity $(56.20 \%)$ are the first three based on college students' aesthetic ideals. And the last three are wealth $(8.80 \%)$, authority $(3.60 \%)$, weirdness $(2.20 \%)$. Obviously, college students tend to have a positive attitude in the pursuit of beauty, and the top three aesthetic ideals fully reflect the unity of "truth, kindness and beauty".

The results are shown in Table 6 by comparing college students of different genders, studengts' origin, and educational level. It is found that college students of different genders have extremely significant differences in ticking "truth" and "wisdom". The proportion of male college students ticking the former is significantly higher than that of female college students, while the latter is on the contrary. No significant differences were found in the selection of aesthetic ideals among college students from different places. College students of different educational levels have very significant differences in the selection of "kindness, vogue, truth, wealth, authority and wisdom". Among them, the proportion of undergraduates who check "fashion and wealth" is significantly higher than that of postgraduate. On the contrary, the proportion of postgraduates who check "kindness, truth, authority and wisdom" is significantly higher than that of undergraduates. 
Table 6: Comparison of college students' aesthetic ideal

\begin{tabular}{|c|c|c|c|c|c|c|c|c|c|}
\hline & \multicolumn{2}{|c|}{ Gender } & \multirow[b]{2}{*}{$\chi^{2}$} & \multicolumn{2}{|c|}{ Location of Their Home } & \multirow[b]{2}{*}{$\chi^{2}$} & \multicolumn{2}{|c|}{ Qualification } & \multirow[b]{2}{*}{$\chi^{2}$} \\
\hline & $\begin{array}{c}\text { Male } \\
(\%)\end{array}$ & $\begin{array}{c}\text { Female } \\
(\%)\end{array}$ & & $\begin{array}{c}\text { Countryside } \\
(\%)\end{array}$ & City (\%) & & $\begin{array}{c}\text { Undergraduate } \\
(\%)\end{array}$ & $\begin{array}{c}\text { Postgraduate } \\
(\%)\end{array}$ & \\
\hline Kindness & 69.50 & 71.20 & 0.36 & 67.50 & 59.30 & 3.29 & 67.60 & 79.90 & $14.02 * *$ \\
\hline Vogue & 12.40 & 15.90 & 2.48 & 15.20 & 14.70 & 0.17 & 16.70 & 8.30 & $10.92 * *$ \\
\hline Truth & 27.60 & 17.00 & $16.66^{* * *}$ & 21.30 & 20.50 & 0.08 & 20.60 & 21.70 & 0.14 \\
\hline Wealth & 8.70 & 8.80 & 0.01 & 9.80 & 8.00 & 1.02 & 10.00 & 4.70 & $6.81^{* *}$ \\
\hline Authority & 5.00 & 2.80 & 3.27 & 4.40 & 3.00 & 1.41 & 4.50 & 0.80 & $7.69 * *$ \\
\hline Wisdom & 56.80 & 69.00 & $15.69 * *$ & 64.30 & 64.60 & 0.04 & 62.20 & 72.00 & $8.11^{* *}$ \\
\hline Harmony & 26.60 & 27.10 & 0.04 & 28.50 & 25.80 & 0.91 & 27.40 & 25.60 & 0.30 \\
\hline Sincerity & 58.90 & 54.70 & 1.78 & 53.50 & 58.10 & 2.18 & 57.50 & 22.50 & 2.04 \\
\hline Weirdness & 1.60 & 2.50 & 1.033 & 2.10 & 2.20 & 0.025 & 2.60 & 0.80 & 3.071 \\
\hline
\end{tabular}

Annotation: * mean $\mathrm{P}<0.05$, great difference; $* *$ mean $\mathrm{P}<0.01$, significant difference.

Table 7: Keywords frequency statistics of recognition of beauty

\begin{tabular}{|c|c|c|c|}
\hline Frequency & Keywords & Frequency & Keywords \\
\hline 192 & pleasure & 11 & art \\
\hline 72 & objective things & 10 & common \\
\hline 57 & ersonal standards (difficult to express) & 9 & beautiful、 fine \\
\hline 28 & inner feelings & 7 & generous, physical and mental pleasure, genuine \\
\hline 26 & Inherent, beautification of mind & 6 & $\begin{array}{l}\text { law, global thinking and local operation, look forward } \\
\text { to }\end{array}$ \\
\hline 24 & kindness & 5 & $\begin{array}{l}\text { appropriate, goodliness, appreciation of the beauty, } \\
\text { appreciate, novelty }\end{array}$ \\
\hline 21 & $\begin{array}{l}\text { harmony, external, subjective } \\
\text { experience }\end{array}$ & 4 & charm, quality, physical and mental experience \\
\hline 16 & good-looking & 4 & life, natural beauty, self-confidence \\
\hline 15 & suitable & 3 & touched, resonance, good, ability, cognition \\
\hline 14 & temperament & 3 & vision, comfortable, shock, pursue \\
\hline
\end{tabular}

Table 8: Comparison of aesthetic behavior field of college students

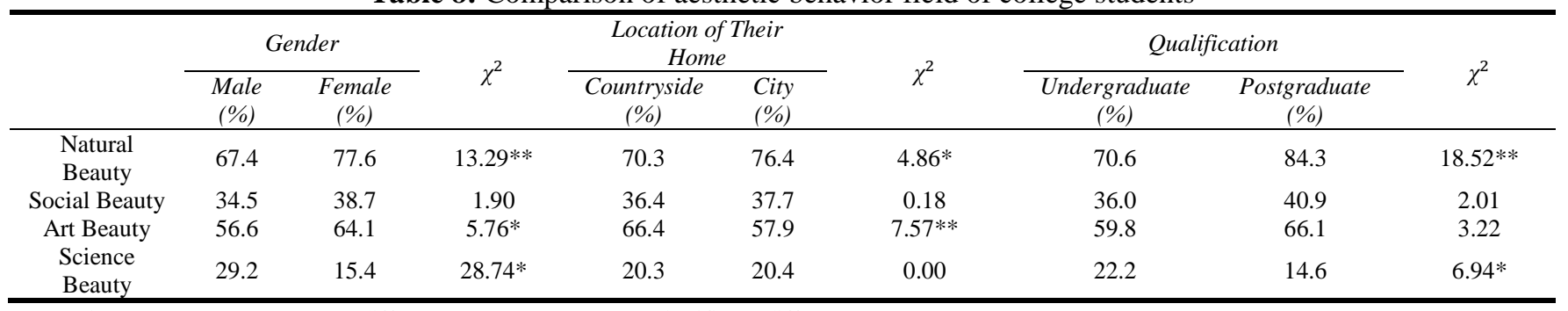

Annotation: * mean $\mathrm{P}<0.05$, great difference; $* *$ mean $\mathrm{P}<0.01$, significant difference.

\subsubsection{Aesthetic common sense of college students}

First of all, college students' understanding of beauty. What is beauty the most basic question of aesthetic common sense. In the study of aesthetics, different scholars have made different interpretations of the essence of beauty. For college students, the answer to "what is beauty" should be based not only on their own aesthetic experience, but also on the knowledge base of personal professional and even extracurricular reading. The survey with using a question-and-answer format, and the collected answers are analyzed by keyword research tool. The inquiry found that "pleasure, objective things, personal standards (difficult to express)" are the first three with the highest frequency, which respectively represent "beauty is subjective", "beauty is objective", and "beauty is different to each person". In the following keywords, there are expressions of understanding of beauty from the category of beauty, such as "shock", and some understanding of beauty from the field of expressions of beauty, such as "natural beauty".

In addition, it directly expresses features of beauty, such as "beautiful", "generous", "comfortable", etc. There are also words that equate beauty with kindness, virtue, quality, and temperament. Therefore, it can be seen that college students' understanding of beauty presents a variety of characteristics, and the understanding of beauty based on the existing aesthetic experience mostly answers the question of "what is beautiful" and avoids the question of "what does beauty really mean".

Secondly, college students' understanding of aesthetics. Aesthetics, as the science of study of beauty, sense of beauty and art[7]. College students' understanding of aesthetics puts more emphasis on the theoretical understanding of beauty in the whole education. The survey with using a question-andanswer format, and the collected answers are classified and analyzed statistically. The results show that most college students' understanding of aesthetics is similar to the academic definition of aesthetics, that is, aesthetics is the learning of beauty.

Thirdly, college students' understanding of aesthetic education. Aesthetic education is an important part of the party and the country's education policy, and the education policy of comprehensive development of morality, intelligence, physical education, beauty and labor has been deeply rooted in the hearts. College students' understanding 
of aesthetic education not only represents the basic aesthetic quality, but also reflects the implementation of aesthetic education in preschool, elementary and secondary education they have received. The survey with using a question-andanswer format, and the collected answers are classified and analyzed statistically. The result finds that there are still a small number of college students who have misunderstandings about aesthetic education, which is cosmetology and hairdressing education and education for interaction with the United States. Nearly $30 \%$ of college students narrowly understand aesthetic education as art appreciation education. Nearly $70 \%$ of college students have a relatively complete understanding of aesthetic education. This is more consistent with the current implementation of aesthetic education. On the one hand, lack of aesthetic education has caused a misunderstanding of aesthetic education. On the other hand, it replaces the function of aesthetic education with art education and directs aesthetic education to art education.

\subsubsection{Aesthetic behavior of college students}

Firstly, the field of aesthetic behavior of college students. From the perspective of different college aesthetic education textbooks, college students' aesthetic behaviors include at least natural beauty, social beauty, artistic beauty and scientific beauty. Different college students' choices of aesthetic objects and aesthetic behaviors directly express their aesthetic needs and characteristics. The types of college students' aesthetic behavior are divided into the above four categories, and data are collected in the form of multiple choice questions. The results found that: $73.9 \%$ of college students choose nature, $61.4 \%$ of college students choose art, and still $7.1 \%$ of college students have no clear choice.

By comparing college students of different gender, location of their home, and educational level, many differences are found. For example, female choose natural and artistic beauty more than male, while scientific beauty is just the opposite. College students from cities have higher awareness of their own natural aesthetic behaviors than rural college students, and the opposite is true in terms of artistic beauty. Postgraduates appreciate natural beauty more than undergraduates, while scientific beauty is the opposite.
Secondly, the types of aesthetic activities of college students. Leisure activities are the main way of college students' aesthetic activities, reflecting the tendency of college students' aesthetic activities. The survey sets up ten kinds of common activities on university campuses and conductes the survey in the way of multiple choices. The results show that appreciating natural scenery $(76.5 \%)$, appreciating or creating film and television (59.9\%), and appreciating or creating music $(59.6 \%)$ are the first three of leisure aesthetic activities. The last three items are appreciating or imitating idols (14.2\%), appreciating or participating in technological activities $(23.7 \%)$ and appreciating or participating in other artistic activities such as dance (37\%). The first three activities that college students like can be colloquially understood as "watching the natural scenery, videos and listening to music", which shows that the leisure activities of college students are simple and easy to obtain. Therefore, there are fewer people choosing dance art and technology activities which need to use their hands and brains.

By comparing college students of different gender, location, and educational background, the results are shown in Table 9. In the appreciation or creation of literature activity, there are obviously more boys than girls, and more postgraduates than undergraduates. In the activities of appreciating, visiting or creating art, there are more girls than boys, and there are obviously more college students in rural areas than urban college students, and more undergraduates than postgraduates. In the activities of appreciating or creating music and appreciating or creating film and television, there are more postgraduates than undergraduates. In appreciating or participating in other artistic activities like dance, there are obviously more girls than boys, and more undergraduates than postgraduates. In the appreciation of natural scenery activity, there were obviously more urban college students than rural college students, and more postgraduates than undergraduates. In the activity of growing flowers and pets, there were obviously more girls than boys. In appreciating or participating in $R \& D$ activities, there are obviously more boys than girls, more rural college students than urban, and more undergraduates than postgraduates. In the activities of appreciating or imitating idols, there are obviously more undergraduates than postgraduates.

Table 9: Comparison of college students' aesthetic activities

\begin{tabular}{|c|c|c|c|c|c|c|c|c|c|}
\hline & \multicolumn{2}{|c|}{ Gender } & \multirow[b]{2}{*}{$\chi^{2}$} & \multicolumn{2}{|c|}{ Location of Their Home } & \multirow[b]{2}{*}{$\chi^{2}$} & \multicolumn{2}{|c|}{ Qualification } & \multirow[b]{2}{*}{$\chi^{2}$} \\
\hline & $\begin{array}{l}\text { Male } \\
(\%)\end{array}$ & $\begin{array}{c}\text { Female } \\
(\%)\end{array}$ & & $\begin{array}{c}\text { Countryside } \\
\text { (\%) }\end{array}$ & $\begin{array}{l}\text { City } \\
(\%)\end{array}$ & & $\begin{array}{c}\text { Undergraduate } \\
(\%)\end{array}$ & $\begin{array}{c}\text { Postgraduate } \\
(\%)\end{array}$ & \\
\hline $\begin{array}{l}\text { Appreciating or Creating } \\
\text { Literature }\end{array}$ & 54.74 & 44.86 & $9.48 * *$ & 49.07 & 47.99 & 0.12 & 46.30 & 55.12 & $6.00 *$ \\
\hline $\begin{array}{c}\text { Appreciating, Visiting or } \\
\text { Creating Art }\end{array}$ & 32.11 & 39.20 & $5.25 *$ & 42.06 & 32.91 & $9.15 * *$ & 40.03 & 25.98 & $16.36 * *$ \\
\hline Appreciating or Creating Music & 61.32 & 58.57 & 0.76 & 60.00 & 59.20 & 0.07 & 57.72 & 65.35 & $4.67 *$ \\
\hline $\begin{array}{l}\text { Appreciating or Creating Film } \\
\text { and Television }\end{array}$ & 59.74 & 59.91 & 0.01 & 62.15 & 58.27 & 1.59 & 57.72 & 66.54 & $6.23 *$ \\
\hline $\begin{array}{c}\text { Appreciating or Participating in } \\
\text { Other Srtistic Activities like } \\
\text { Dance }\end{array}$ & 28.16 & 42.32 & $20.84 * *$ & 37.62 & 36.92 & 0.05 & 40.03 & 28.35 & $11.25 * *$ \\
\hline Appreciating Natural Scenery & 74.47 & 77.50 & 1.23 & 72.20 & 79.29 & $7.09 * *$ & 73.53 & 85.43 & $15.15^{* *}$ \\
\hline Growing Flowers and Pets & 38.16 & 48.58 & $10.66 * *$ & 45.09 & 44.62 & 0.02 & 45.67 & 42.13 & 0.98 \\
\hline $\begin{array}{c}\text { Appreciating or Participating in } \\
\text { R\&D }\end{array}$ & 34.21 & 17.73 & $36.43 * *$ & 27.80 & 20.87 & $6.75^{* *}$ & 25.60 & 17.72 & $6.62 *$ \\
\hline Appreciating or Imitating Odols & 12.14 & 15.35 & 2.05 & 14.72 & 13.83 & 0.17 & 15.95 & 8.66 & $8.41 * *$ \\
\hline
\end{tabular}

Annotation: * mean $\mathrm{P}<0.05$, great difference; $* *$ mean $\mathrm{P}<0.01$, significant difference. 


\subsection{Temand for College Students' Aesthetic Education Curriculums}

The design of aesthetic education curriculum is based on the needs of college students, while considering the aesthetic education curriculum provided at the primary education stage, and unifying it as the knowledge base of aesthetic education in colleges and universities. According to this point of view, the survey of the needs of college students' aesthetic education courses starts from the students' mastery of basic artistic skills, and investigates the general situation of the students' art education, professional aesthetic courses and inter-professional aesthetic cognition.

\subsubsection{General situation of art education or curriculums}

Art education is an important link in the implementation of aesthetic education. The art skills and training received by college students reflect the implementation of art education.

Firstly, college students master artistic skills. Artistic skills are the basis for college students to participate in artistic activities. Chorus, instrument, painting, dance or gymnastics are selected as alternatives (the last option "none" is a single choice, otherwise it is an invalid questionnaire, the same below). The survey with multiple choice show that the main artistic skills mastered by college students include painting (30.1\%), instrument $(24.7 \%)$, chorus $(23.2 \%)$, etc. The most important thing to pay attention to is that nearly $40 \%$ of college students haven't mastered any kind of artistic skills. This shows that in the reality of such development of art training, music, arts and other art courses in elementary education don't play the basic role of art education.

Secondly, college students receive art training. National curriculum standards stipulate corresponding art courses such as music, art, and etc.. At the same time, some parents purchase social education and training services to provide art training for their children. Among college students with artistic skills, it can be seen from the results that the main types of art training received by college students include music, art, and dance. The time for art training received by students is relatively evenly distributed. Nearly $30 \%$ of college students have received art training in junior high school and previous education stages, and that they received art training is mainly school education $(68.4 \%)$, followed by after-school tutoring classes (64.1\%) and self-study (31.6\%). $77.1 \%$ of college students receive art training is to enrich their after-school life and $79.5 \%$ is to improve their aesthetic ability. $8.1 \%$ of college students receive art training as required by their parents or higher education.

Thirdly, the attitude of college students towards artistic skills. Mastering artistic skills is an important part of the leisure aesthetic activities of college students, and its level is mainly divided into two categories: amusing themselves and professional performance. From the investigation, more than $70 \%$ of college students hope to master artistic skills for selfentertainment, and more than $40 \%$ of them hope to have multiple artistic skills. Only $5.7 \%$ of college students have no expectations for artistic skills.
3.2.2 General situation of aesthetic education curriculums of subjects and specialities

Majors are the basic units of higher education, and the aesthetic perception of majors is an important emotional basis for college students to learn professional knowledge, conduct professional research, and engage in professional work.

Firstly, college students' aesthetic understanding of the major. The prerequisite and foundation of professional aesthetic recognition is whether college students love and are affected. The result of a single-choice question survey found that more than $70 \%$ of college students love their own majors, and less than $20 \%$ of college students dislike their majors. The survey in the form of question-and-answer questions found that college students were moved by their majors mainly in the professional skills, values, characteristics, teaching content and learning atmosphere, they gained and experienced. Among, in terms of professional skills, the main points include: to understand more modern historical events, to understand foreign literature, to survive, to cultivate one's own solid basic skills, to explore the laws of social and economic operation, to explore the mysteries of beauty, and to pass professional operations can heal patients, and promote the development of modern higher education, to understand the status quo of China's cultural industry, be able to find inadequate parts of business management, be able to record economic activities, be able to focus on the real problems of education, be able to shoot beautiful things..... In terms of professional value, the main points include: sincere concern for education, concern and care for people, unremitting pursuit of knowledge and truth, sense of responsibility, respect for nature, justice and rule of law, national honor, teamwork spirit, serving the people, acting as a teacher, contributing to the development of the network, belief and mission, persistence of scholars, rigorous scientific research attitude..... In terms of educational content, it mainly includes: the process from drawings to products, the succinct symmetry of codes and formulas, attention to national affairs and world affairs and human life, national economic policy, Chinese studies, painting, aerobics, inter-period value exchange, the precious spiritual wealth for mankind left by Marx and Engels, national culture, human game rules, social crime prevention, videography, experimental phenomena, market fluctuations, childhood, literature and art, mental health consultation, information, research on national economy and traditional Chinese medicine and doctor, using mathematics model studies economic issues, long-standing Chinese culture, speed of movement, order..... In terms of professional characteristics, the main points of view include: more practical, creative, hands-on, physical exercise, reading more, multi-solutions to solve problems, multi-directional development, wide range of work and relatively stable, comprehensive, concise, profound and powerful, broad knowledge, subtle, exquisite, precise, the combination of science and art, strive for accuracy, long history, busy, wonderful, relaxed, versatile, profound and huge, magical, conform to the trend of the times, close to life, systematic, meticulous and serious, truthful and popular, and cover a wide range of expertise...... In the learning atmosphere, it is mainly reflected in teacher-student exchanges and a sense of collectiveness: the rigorous academic attitude of the tutor, the 
dedication of the teacher, the number of famous teachers, the meeting of a group of like-minded people, the compatibility and interaction, the teacher-student relationship, the spring breeze, the class collective, everyone wakes up early and sleeps late to study...... Others include opinions that are in line with personal interests and majors are popular. Therefore, different majors give college students different touches, which in fact reflects their professional identity, and results in a heartfelt and pleasant physical and mental experience.

Secondly, the establishment of aesthetic education curriculums for different majors. Whether university offers aesthetic education curriculums is an important manifestation of meeting the needs of college students' aesthetic education and the requirements of higher education development. It is worth noting that the curriculum of aesthetic education in colleges and universities mustn't be limited to art appreciation, and the aesthetic understanding and aesthetic teaching of the major is more important. In addition, for college students, what kind of aesthetic education courses they expect to offer directly reflects their needs. Results: $88.2 \%$ of the majors didn't offer relevant professional aesthetic courses. Regarding the expectations of aesthetic education courses, the survey found that college students have the highest demand for professional aesthetic courses, followed by art appreciation courses and life aesthetics courses.

\subsubsection{General situation of interdisciplinary aesthetic education curriculums}

Beauty is omnipresent, and any existence that conforms to the laws of beauty can produce beauty. Since beauty exists in all areas of people's lives, all aesthetic objects of natural, social beauty, and artistic beauty may become teaching materials for aesthetic education. [8] College students' understanding of the beauty of different disciplines reflects their ability to create a beautiful life based on a certain aesthetic experience and theory, rather than just relying on art appreciation or artistic techniques to obtain aesthetic experience. Furthermore, the interdisciplinary development of aesthetic ability is used to realize the comprehensive development of personality. Multiple-choice questions are on the topic of beauty in different fields. The results found that nearly half of the students who chose the two fields, nearly $20 \%$ of all, only $6.5 \%$ of college students believed that beauty don't coexist in these fields. From the perspective of various choices, $67.60 \%$ of students chose "nature", $46.50 \%$ of them chose "society", $70.90 \%$ chose "art", and $41.20 \%$ chose "science". Therefore, natural and artistic beauty are still the main areas where college students' aesthetic objects exist.

\section{Findings and Conclusions}

\subsection{Many Students Still LackBasic Aesthetic Knowledge and Skills}

The aesthetic consciousness, common sense and behavior of college students show the following characteristics:

(1) College students have strong aesthetic consciousness, and there are obvious differences in the two dimensions of gender and qualification.
(2) The aesthetic standards of college students are mainly in personal interests and hobbies, and there is no significant difference in the three dimensions.

(3) College students maintain a tolerant attitude towards aesthetic judgments of in-thing, and only male and female students have significant differences in their views on plastic surgery.

(4) College students' aesthetic ideals are led by kindness, wisdom and sincerity, and there are significant differences in different dimensions.

(5) College students have certain aesthetic common sense, and their understanding of beauty, aesthetics and aesthetic education is relatively correct, but there are also wrong views that cannot be ignored.

(6) The aesthetic behaviors of college students are mainly in nature and art, and scientific aesthetic behaviors are the least, and there are significant differences in different dimensions.

(7) The types of aesthetic activities are mainly simple, accessible and foolproof, and there are significant differences in different dimensions.

\subsection{The Existing Curriculum System Still Cannot Meet the Various Needs of College Students'Aesthetic Education}

The demand for college students' aesthetic education courses in art education, aesthetic education of discipline and speciality, and interdisciplinary aesthetic education show the following characteristics:

(1) Nearly $40 \%$ of college students haven't learned art skills and techniques.

(2) The art skills training that college students receive is mainly concentrated before high school, mainly in the fields of music, art and dance. After-school tutoring and self-study are important ways of college students' art training.

(3) The main purpose of college students learning artistic skills is to improve their aesthetic ability and hope to acquire a number of artistic skills for amusing themselves.

(4) Most college students like their majors and certainly recognize the beauty of majors, but most majors don't have a list of corresponding aesthetic courses on offer.

(5) College students have a certain understanding of the interdisciplinary existence of beauty, which is mainly concentrated in the fields of nature and art.

4.3 Aesthetic Education Curriculum in Colleges and Universities Should Make up the Basic Ability of Beautyappreciation, and the Sbility to Develop Majors and Interdisciplinary Aesthetic

In view of college students' strong aesthetic awareness and demand for aesthetic education courses, aesthetic education should assume the dual tasks of compensation and development. 
First of all, aesthetic education curriculums in colleges and universities should be face all students. Universities must be able to provide higher-level aesthetic education curriculums for college students with high aesthetic standards and good aesthetic qualities, and also provide compensating courses for college students who is behind, choose appropriate aesthetic experience and skills. Through the technical approach to provide students with various curriculums, which is applicable to students' interests and achieve development of aesthetic quality.

Secondly, provide completely compensatory and developmental course content. According to the results of the survey, the basic knowledge and skills of aesthetic appreciation should include at least basic artistic skills, art history of designated subjects, etc.. And the design of professional and interdisciplinary aesthetic appreciation should be based on advanced knowledge such as the essence of beauty, the laws of beauty, and the principles of beauty, which is an important part of college students' majors.

Thirdly, according to Marx's point of view, "people build objects according to the laws of beauty, and they also shape themselves in accordance with the laws of beauty." To realize the education of life values in aesthetic education, the aesthetic appreciation of life and design of beautiful life should be included in the curriculum content.

All in all, based on current findings, college students' aesthetic awareness, common sense and behavior have shown a certain diffusion trend. The inclusive and personalized characteristics of their aesthetic thoughts are more obvious and the demands of aesthetic education courses are given greater prominence. At the same time, it should be noted that there are still many college students' aesthetic appreciation is cracking during the process of discovery, appreciation, feeling and creation of beauty, and even lacking of some basic artistic attempts. As a curriculum goal, aesthetic quality involves the knowledgeable appreciation of art. [9] It still cannot meet the requirements of current education development and talent training. The construction of the aesthetic education system in colleges and universities still has a long way off, and the exploration of aesthetic education curriculums is of primary importance.

\section{Acknowledgments}

This paper is supported by the fund project: Liupanshui Normal University scientific research projects (No. LPSSYSK202016) and the Guizhou Provincial Education Department Foundation Project (No. 2021QN006).

\section{References}

[1] Greene M. Variations on a Blue Guitar: The Lincoln Center Institute Lectures on Aesthetic Education[M]. Williston: Teachers College Press, 2001.

[2] Zhao Lingli, Wang Hong. Empirical Studies on Aesthetic Psychology[M]. Beijing: Peking University Press, 2010.
[3] Huang Xiting, Yang Zhiliang, Lin Chongde. Dictionary of Psychology[M]. Shanghai: Shanghai Education Press, 2003.

[4] Hamblen, Karen A. Exploring Contested Concepts for Aesthetic Literacy[J]. Journal of Aesthetic Education 20, no. 2 (1986): 67-76.

[5] Zhao Lingli, Wang Hong. Empirical Studies on Aesthetic Psychology[M]. Beijing: Peking University Press, 2010.

[6] Che Wenbo. Encyclopedia of Psychological Counseling [M]. Changchun: Jilin People's Publishing House, 1991.

[7] Yang Xin, Gan Lin. Aesthetic Principles [M]. Beijing: Peking University Press, 2018.

[8] Wang Min, Zeng Fanren. Modern Construction of College Aesthetic Education System [J]. China Higher Education, 2017(07): 7-10.

[9] Hamblen, Karen A. Exploring Contested Concepts for Aesthetic Literacy[J]. Journal of Aesthetic Education, 1986, 20(2): 67-76. 